\title{
Study on the Effect of Web-Based Real-Time Interactive Intervention Teaching Model on Self-Efficacy of Gestational Diabetes Mellitus Patients
}

\author{
Yu Yang*, Qiuying Lin*, Pingping Quan\#, Yanmei Wen, Xuyao Li, Jufang Lin \\ Department of Obstetrics, The Third Affiliated Hospital of Sun Yat-sen University, Guangzhou, China \\ Email: 294597586@qq.com, jumpfaraway@126.com, ${ }^{*} 1787927262 @ q q . c o m ~$
}

How to cite this paper: Yang, Y., Lin, Q.Y., Quan, P.P., Wen, Y.M., Li, X.Y. and Lin, J.F. (2020) Study on the Effect of WebBased Real-Time Interactive Intervention Teaching Model on Self-Efficacy of Gestational Diabetes Mellitus Patients. International Journal of Clinical Medicine, 11, 778785.

https://doi.org/10.4236/ijcm.2020.1112058

Received: October 15, 2020

Accepted: December 14, 2020

Published: December 17, 2020

Copyright $\odot 2020$ by author(s) and Scientific Research Publishing Inc. This work is licensed under the Creative Commons Attribution International License (CC BY 4.0).

http://creativecommons.org/licenses/by/4.0/

\begin{abstract}
Object: To explore the effect of web-based real-time interactive intervention teaching model on self-efficacy of Gestational Diabetes Mellitus (GDM) patients. Method: Based on the hospital's antenatal check-up archives from June 2018 to January 2019, patients diagnosed with GDM in the second trimester were randomly divided into the control group (100 cases) and the experimental group (121 cases). Patients in the control group received routine care following the diabetes mellitus one-day outpatient guidance, while patients in the experimental group received social media real-time interactive teaching intervention based on routine care, and accepted a nursing intervention scheme based on knowledge-attitude-practice mode. The knowledge of GDM, self-efficacy and self-management behavior indicators were compared between the two groups. Results: After the intervention, the self-efficacy scores, the blood glucose monitoring times and the blood glucose compliance rates of the experimental group were significantly higher than those of the control group $(P<0.05)$. The post-intervention GDM knowledge scores of the experimental group were higher than those of the control group, and the difference was not statistically significant $(P=0.072)$. Conclusion: Web-based realtime interactive intervention teaching model can effectively improve the selfefficacy of GDM patients and promote the formation of healthy behaviors.
\end{abstract}

\section{Keywords}

Web-Based, Gestational Diabetes Mellitus, Self-Efficacy,

Knowledge-Attitude-Practice Mode

${ }^{*}$ Both are the first authors. 


\section{Introduction}

Gestational Diabetes Mellitus (GDM) is a pregnancy comorbidity that presented normal before pregnancy yet has different degrees of abnormal glucose metabolism during pregnancy [1]. The International Diabetes Federation (IDF) announced that the global incidence of hyperglycemia during pregnancy in pregnant women aged 20 - 49 in 2019 was $15.8 \%$, of which the incidence of GDM was $13.21 \%$ [2]. With the improvement of residents' living standards, the incidence of gestational diabetes in China has increased substantially in the past 10 years, and its prevalence has reached $17.5 \%$ [3]. GDM will cause a series of short-term and longterm adverse effects on mothers and children. As women's blood glucose levels increase during pregnancy, their risks of premature delivery, cesarean section, shoulder dystocia or birth injury, preeclampsia, and neonatal hypoglycemia also increase [4] [5] [6]. However, the self-management behavior of patients with GDM is not ideal, and the current level of self-management efficacy can barely adapt to the needs of disease treatment [7] [8]. Studies have shown that good, real-time interactive health education interventions have obvious advantages in the short-term effects of blood glucose control and the long-term effects of selfmanagement efficacy [9] [10]. This study explores the effect of web-based realtime interactive intervention teaching model on the self-management efficacy of GDM patients, in order to promote healthy diet and lifestyle of GDM pregnant women, and to provide clinical guidance for promoting the formation of selfmanagement behaviors in patients with GDM.

\section{Materials and Methods}

\subsection{General Information}

Based on the regular antenatal check-ups of our hospital from June 2018 to January 2019, patients diagnosed with GDM in the second trimester of pregnancy were selected as the research subjects, and were randomly divided into 100 cases in the control group and 121 cases in the experimental group. Inclusion criteria: 1) conform to the diagnostic criteria recommended by the Guidelines for the Diagnosis and Treatment of Diabetes in Pregnancy (2014) for GDM diagnosis; 2) single pregnancy, with archive file setting up in our hospital and plan to give birth in our hospital; 3) skilled use of mobile social media; 4) no mental illness or severe heart, liver and kidney dysfunction, and no intellectual or speech disorders; 5) informed consent. Exclusion criteria: 1) with severe complications or comorbidity; 2) communication disorders or mental disorders. The pregnant women cases in the control group were 21 - 44 years old, with an average age of (33.96 \pm 5.12) years; educational level: 6 cases were at the level of junior high school and below, while 22 were high school, 29 were junior college, and 43 were bachelor and above. The cases in the experimental group were 22 - 43 years old, with an average age of $(33.15 \pm 5.13)$ years; educational level: 6 cases were at the level of junior high school and below, 29 cases were high school, 29 cases were junior college, and 57 cases were bachelor degree and above. There was no sig- 
nificant difference in age and educational level between the two groups of patients $(P>0.05)$, and they were comparable (Table 1$)$.

\subsection{Methods}

\subsubsection{Interventional Methods}

The control group received routine care following the diabetes mellitus one-day outpatient guidance that instructed on the theoretical knowledge, diet, exercise, blood glucose monitoring, etc. The experimental group received social media real-time interactive teaching intervention based on the control group's routine care, and adopted a nursing intervention scheme based on knowledge-attitudepractice mode. Jointly discussed and formulated by an obstetrician, an obstetrical chief nurse and two nurses-in-charge, the nursing intervention scheme was based on the three stages of the "knowledge-attitude-practice" theoretical model, namely acquiring knowledge, generating attitudinal belief, and forming practice. See Table 2 for details.

\subsubsection{Observation Indicators}

1) Comparison of GDM knowledge scores between the two groups before and after intervention. Self-designed GDM knowledge questionnaire with right-orwrong questions was used to measure the patient's cognition level of GDM and the treatment. 1 point for each question, and the total score range was $0-20$ points.

2) Comparison of self-efficacy between the two groups before and after intervention. The diabetes self-efficacy scale developed by Chen Qi et al. [11] was used, which contained 20 items and assessed the extent to which respondents believe that they can manage their blood sugar, diet, and exercise levels. The responses were divided into 11 levels, with 0 points for "completely impossible" and 10 points for "completely possible". The total score ranged from 0 to 200 points. The higher the score, the higher the self-efficacy. Score indicator $=$ (the actual score of the sub-scale/the highest possible score of the scale) $\times 100 \%$. According to the ranking of the score indicators, the self-efficacy was divided into 3 levels: good, fair and poor, where $\geq 80 \%$ was good self-efficacy, $40 \%-80 \%$ was fair self-efficacy, and $\leq 40 \%$ was poor self-efficacy.

Table 1. Comparison of general data of the two groups of pregnant women.

\begin{tabular}{lccc}
\hline Group & $\mathbf{n}=$ & Age & Educational level \\
\hline Control Group & 100 & $33.96 \pm 5.12$ & $\begin{array}{c}\text { Junior high school and below: } 6 \\
\text { High school: } 22 \\
\text { Junior college: } 29\end{array}$ \\
& & Bachelor degree and above: 43 \\
& & & Junior high school and below: 6 \\
& & High school: 29 \\
Experimental Group & 121 & $33.15 \pm 5.13$ & Junior college: 29 \\
& & & Bachelor degree and above: 57 \\
& & $>0.05$ & $>0.05$ \\
\hline
\end{tabular}


Table 2. Intervention methods of the two groups.

\begin{tabular}{|c|c|c|c|c|}
\hline & $\begin{array}{c}\text { Intervention } \\
\text { variables }\end{array}$ & Intervention purpose & Time and methods & Details \\
\hline Control Group & & $\begin{array}{l}\text { Train GDM patients to } \\
\text { complete self-regulation } \\
\text { of diet and blood glucose } \\
\text { monitoring }\end{array}$ & $\begin{array}{l}\text { Day 1: Face-to-face one-day } \\
\text { outpatient health education on } \\
\text { diabetes 1) GDM information } \\
\text { providing; 2) blood glucose } \\
\text { monitoring; 3) diet guidance and } \\
\text { recording; 4) exercise guidance. }\end{array}$ & $\begin{array}{l}\text { 1) Explain the dangers of GDM; 2) weight } \\
\text { management and reasonable diet during pregnancy, } \\
\text { experience the breakfast, lunch and snacks } \\
\text { customized by the nutrition and diet department of } \\
\text { the hospital; 3) exercise during pregnancy, and } \\
\text { practice GDM health exercises for half an hour; } 4 \text { ) } \\
\text { glucose management guidance, teach GDM patients } \\
\text { to monitor blood glucose. }\end{array}$ \\
\hline \multirow{3}{*}{$\begin{array}{l}\text { Experimental } \\
\text { Group }\end{array}$} & Knowledge & $\begin{array}{l}\text { To enhance GDM } \\
\text { patients' awareness of } \\
\text { gestational diabetes }\end{array}$ & $\begin{array}{l}\text { Week 1: Face-to-face one-day } \\
\text { outpatient health education on } \\
\text { diabetes 1) GDM information } \\
\text { providing; 2) blood glucose } \\
\text { monitoring; 3) diet guidance and } \\
\text { recording; 4) exercise guidance. }\end{array}$ & $\begin{array}{l}\text { 1) Explain the pathogenesis of GDM and its harmful } \\
\text { impact on the mothers and the children; 2) weight } \\
\text { management and reasonable diet during pregnancy, } \\
\text { experience the breakfast, lunch and snacks } \\
\text { customized by the nutrition and diet department of } \\
\text { the hospital; 3) exercise during pregnancy, and } \\
\text { practice GDM health exercises for half an hour; 4) } \\
\text { glucose management guidance, teach GDM patients } \\
\text { to monitor blood glucose, explain how to use the } \\
\text { mini program in the WeChat group to record and } \\
\text { share the information of each meal and blood glucose. }\end{array}$ \\
\hline & Attitude & $\begin{array}{l}\text { To promote correct } \\
\text { beliefs and attitudes for } \\
\text { patients with GDM }\end{array}$ & $\begin{array}{l}\text { Weeks } 1 \text { - 6: Interact in the } \\
\text { WeChat group in real time to } \\
\text { engage pregnant women to } \\
\text { participate. Twice a week, } 1 \text { hour } \\
\text { each time. }\end{array}$ & $\begin{array}{l}\text { 1) Share popular science articles in WeChat groups } \\
\text { on the hazards and effects of GDM, key points of diet } \\
\text { control, knowledge of food exchange method, weight } \\
\text { management, reference to normal blood glucose, } \\
\text { recipe recommendations, etc. 2) encourage patients } \\
\text { to monitor their own blood glucose and record their } \\
\text { diets, and provide timely feedback on the uploaded } \\
\text { diet records and blood glucose values; guide a } \\
\text { discussion on topics about diet and exercise once a } \\
\text { week, to inspire patients to summarize and analyze } \\
\text { their own blood glucose and diet exercise. }\end{array}$ \\
\hline & Practice & $\begin{array}{l}\text { To guide the formation } \\
\text { of healthy behaviors for } \\
\text { GDM patients }\end{array}$ & $\begin{array}{l}\text { From the start of intervention to } \\
\text { the end of pregnancy: record with } \\
\text { WeChat mini program, once a } \\
\text { week or once every two weeks. }\end{array}$ & $\begin{array}{l}\text { Instruct the patients to perform self-blood glucose } \\
\text { testing on a regular basis (one day of a week or every } \\
\text { two weeks), use the WeChat mini program to record } \\
\text { meals, and maintain proper exercise until the end of } \\
\text { pregnancy. }\end{array}$ \\
\hline
\end{tabular}

3) Comparison of self-management behavior, frequency of self-blood glucose monitoring and blood glucose compliance rate between the two groups before and after intervention. In this study, the blood glucose compliance rate was defined as: [the number of blood glucose values that met the criteria of the Chinese Guidelines for the Diagnosis and Treatment of Diabetes in Pregnancy (2014)]/ (the total number of measurements) $\geq 80 \%$.

\subsubsection{Statistical Methods}

Statistical software SPSS 25.0 was used for data processing and statistical analysis. Measurement data were expressed as mean \pm standard deviation, and the comparison of indicators between groups was performed by two independent samples t-test and repeated measures analysis of variance. 


\section{Results}

1) The scores of GDM knowledge in the two groups after intervention (Table 3).

2) Self-efficacy scores of the two groups' patients (Table 4).

3) Comparison of self-management behavior indicators between the two groups after intervention (the blood glucose monitoring times, the blood glucose compliance rate, and the value of glycosylated hemoglobin) (Table 5).

\section{Discussion}

The high incidence of GDM and its adverse effects on mothers and children have made GDM patients' blood sugar management more and more attention. Patients with GDM are the main undertakers of their blood glucose management, so their self-management behavior can change the hyperglycemia situation during pregnancy to a large extent. The levels of GDM patients' blood glucose self-management, such as fine control of diet, implementation of exercise therapy and standardized monitoring of blood glucose, can stabilize blood glucose fluctuations, so that patients can pass the pregnancy smoothly and reduce maternal and child complications [12]. In this study, the experimental group

Table 3. Comparison of the knowledge scores of GDM before and after intervention.

\begin{tabular}{cccc}
\hline Group & $\mathbf{n}=$ & Before intervention & After intervention \\
\hline Control & 100 & $12.70 \pm 3.27$ & $19.26 \pm 1.12$ \\
Experimental & 121 & $12.46 \pm 3.05$ & $19.51 \pm 0.96$ \\
$t$ & & 0.557 & -1.809 \\
$P$ & & $>0.05$ & 0.072 \\
\hline
\end{tabular}

Table 4. Comparison of self-efficacy scores.

\begin{tabular}{ccc}
\hline Group & $\mathbf{n}=$ & Scores of self-efficacy \\
\hline Control & 100 & $104.39 \pm 7.30$ \\
Experimental & 121 & $108.55 \pm 8.28$ \\
$t$ & & -3.916 \\
$P$ & & $<0.001$ \\
\hline
\end{tabular}

Table 5. Comparison of self-management behavior indicators after intervention.

\begin{tabular}{cccccc}
\hline Group & $\mathrm{n}=$ & \multicolumn{2}{c}{ Blood glucose monitoring times } & \multicolumn{2}{c}{ Blood glucose compliance rates (\%) } \\
\cline { 3 - 6 } & & $\begin{array}{c}\text { 1 week after } \\
\text { intervention }\end{array}$ & $\begin{array}{c}\text { 6 weeks after } \\
\text { intervention }\end{array}$ & $\begin{array}{c}1 \text { week after } \\
\text { intervention }\end{array}$ & $\begin{array}{c}\text { 6 weeks after } \\
\text { intervention }\end{array}$ \\
\hline Control & 100 & $14.00 \pm 4.19$ & $17.98 \pm 7.54$ & $72.42 \pm 16.72$ & $66.99 \pm 20.96$ \\
Experimental & 121 & $16.71 \pm 5.51$ & $20.92 \pm 8.26$ & $80.32 \pm 17.89$ & $76.08 \pm 28.02$ \\
\hline
\end{tabular}

Seeing from the comparison of blood glucose monitoring times and blood glucose compliance rates after intervention between the two groups, the differences between groups and between different time points were statistically significant $(P<0.05)$. 
received planned information support in stages under the nursing intervention scheme based on the knowledge-attitude-practice mode. The face-to-face one-day outpatient guidance on diabetes at the first week provided basic targeted information to increase GDM patients' awareness of the disease and their own status. The experimental group in this study scored higher on GDM knowledge than the control group, indicating that the web-based real-time interactive intervention teaching model can effectively enhance GDM patients' disease knowledge.

Self-management efficacy refers to people's belief or confidence in their ability to achieve a behavior goal in the specific field; it is the degree of confidence an individual has to complete a specific behavior and achieve the expected result [13]. If patients with GDM can develop good self-management efficiency, making healthy behaviors the norm in their family, it is bound to have a positive impact on the offspring's lifestyle [14]. In this study, the real-time interaction intervention in the WeChat group lasted for six weeks, twice a week and one hour at a time, which fully mobilized the subjective initiative of the pregnant women. Under the active promotion of the intervener and peers in the same period, it positively promoted the GDM patients to form correct beliefs and attitudes on the disease, and ultimately guided the formation of patients' healthy behaviors. Studies have shown that the improvement of self-efficacy can enhance pregnant women's confidence in childbirth and mobilize the enthusiasm of treatment, thereby conducive to blood glucose control, reducing the occurrence of postpartum complications [15]. In this study, the self-efficacy scores of the experimental group were higher than those of the control group after six weeks of intervention. The difference was statistically significant, indicating that periodical and regular immediate intervention has a positive effect on the improvement of patients' self-management efficiency.

In this study, the two groups of patients had differences in the blood glucose monitoring times and the blood glucose compliance rates at one week after the intervention and six weeks after the intervention. Among them, the blood glucose monitoring times continued to increase with the passage of the intervention time, which shows that the six-week uninterrupted information output has contributed to the improvement of patients' self-management awareness and precise blood glucose control emphasis. In the results of this study, the blood glucose compliance rate decreased with the intervention time. This may be due to the fact that the increase in blood glucose levels that meet the criteria of the Chinese guidelines for the diagnosis and treatment of gestational diabetes mellitus is lower than the increase in the total number of blood glucose measurements. At the same time, there were differences in the blood glucose monitoring times and blood glucose compliance rates between the two groups at each intervention time point, and those of the experimental group was all higher than those of the control group, which shows that the real-time interactive intervention teaching model can continue to effectively promote the formation of self-management behaviors, and improve the GDM pregnant women's follow-up healthy behavior pattern simultaneously. It has important guiding significance for the mainten- 
ance of later behavior.

\section{Funding}

Nursing Research Fund Project of The Third Affiliated Hospital of Sun Yat-sen University (201809).

\section{Conflicts of Interest}

The authors declare no conflicts of interest regarding the publication of this paper.

\section{References}

[1] Coustan, D.R. (2013) Gestational Diabetes Mellitus. Clinical Chemistry, 59, 13101321. https://doi.org/10.1373/clinchem.2013.203331

[2] IDF Diabetes Atlas 9th Edition 2019. https://www.diabetesatlas.org/en

[3] Zhu, W.W., Yang, H.X., Wei, Y.M., et al. (2013) Evaluation of the Value of Fasting Plasma Glucose in the First Prenatal Visit to Diagnose Gestational Diabetes Mellitus in China. Diabetes Care, 36, 586-590. https://doi.org/10.2337/dc12-1157

[4] Metzger, B.E., Lowe, L.P., Dyer, A.R., et al. (2008) Hyperglycemia and Adverse Pregnancy Outcomes. New England Journal of Medicine, 358, 1991-2002. https://doi.org/10.1056/NEJMoa0707943

[5] Johns, E.C., Denison, F.C., Norman, J.E., et al. (2018) Gestational Diabetes Mellitus: Mechanisms, Treatment, and Complications. Trends in Endocrinology \& Metabolism, 29, 743-754. https://doi.org/10.1016/j.tem.2018.09.004

[6] Damm, P., Houshmand-Oeregaard, A., Kelstrup, L., et al. (2016) Gestational Diabetes Mellitus and Long-Term Consequences for Mother and Offspring: A View from Denmark. Diabetologia, 59, 1396-1399. https://doi.org/10.1007/s00125-016-3985-5

[7] Su, J.B., Wang, X.Q., Chen, J.F., et al. (2013) Glycemic Variability in Gestational Diabetes Mellitus and Its Association with $\beta$ Cell Function. Endocrine, 43, 370-375. https://doi.org/10.1007/s12020-012-9753-5

[8] Wah, Y., McGill, M., Wong, J., et al. (2019) Self-Management of Gestational Diabetes among Chinese Migrants: A Qualitative Study. Women Birth, 32, e17-e23. https://doi.org/10.1016/j.wombi.2018.03.001

[9] Mackillop, L., Hirst, J.E., Bartlett, K.J., et al. (2018) Comparing the Efficacy of a Mobile Phone-Based Blood Glucose Management System with Standard Clinic Care in Women with Gestational Diabetes: Randomized Controlled Trial. JMIR Mhealth Uhealth, 6, e71. https://doi.org/10.2196/mhealth.9512

[10] Mohebbi, B., Tol, A., Sadeghi, R., et al. (2019) Self-Management Intervention Program Based on the Health Belief Model (HBM) among Women with Gestational Diabetes Mellitus: A Quazi-Experimental Study. Archives of Iranian Medicine, 22, 168-173.

[11] Chen, Q., Wang, Z.Z., Chen, Y.H., et al. (2016) Evaluation of Reliability and Validity of Diabetes Management Self-Efficacy Scale in Outpatients in Shanghai Tertiary Hospitals. Journal of Shanghai Jiao Tong University (Medical Edition), 36, 724-729.

[12] Association AAD (2015) Standards of Medical Care in Diabetes 2015. Diabetes Care, 31, S12-S54. https://doi.org/10.2337/dc08-S012

[13] Bandura, A. (1997) Self-Efficacy: The Exercise of Control. W. H. Freeman and Com- 
pany, New York.

[14] Wu, X., Guo, X. and Zhang, Z. (2019) The Efficacy of Mobile Phone Apps for Lifestyle Modification in Diabetes: Systematic Review and Meta-Analysis. JMIR Mhealth Uhealth, 7, e12297. https://doi.org/10.2196/12297

[15] Al-Hashmi, I., Hodge, F., Nandy, K., et al. (2018) The Effect of a Self-Efficacy-Enhancing Intervention on Perceived Self-Efficacy and Actual Adherence to Healthy Behaviours among Women with Gestational Diabetes Mellitus. Sultan Qaboos University Medical Journal, 18, e513-e519.

https://doi.org/10.18295/squmj.2018.18.04.014 